\title{
Penerapan Media Pembelajaran Bahasa Arab Berbasis Android di MA Salafiyah Kota Cirebon
}

\author{
Mohamad Aris \\ Institut Agama Islam Negeri (IAIN) Syekh Nurjati Cirebon \\ Email: aris.alghazali14@gmail.com \\ Erfan Gazali \\ Institut Agama Islam Negeri (IAIN) Syekh Nurjati Cirebon \\ Email: erfangazali@yahoo.com
}

\begin{abstract}
Abstrak
Penelitan ini bertujuan untuk mendeskripsikan bagaimana proses penerapan media pembelajaran bahasa arab berbasis android di kelas sepuluh MA Salafiyah kota cirebon dan persepsi siswa terhadap penerapan media pembelajaran bahasa arab berbasis android. Dasar penelitian ini adalah bahwasanya pembelajaran yang menggunakan media teknologi memberikan pengaruh yang cukup signifikan terhadap pembelajaran. Perangkat android saat ini sangat dekat dengan kehidupan siswa, selain sebagai fungsi komunikasi, perangkat android juga sangat berpotensi dikembangkan menjadi media pembelajaran inovatif dan interaktif yang bermanfaat bagi siswa. Penelitian ini merupakan penelitian kombinasi (mixed methods), yaitu langkah penelitian dengan menggabungkan dua bentuk pendekatan dalam penelitian, yaitu pendekatan kualitatif dan kuantitatif dengan desain penelitian (squential exploratory) yaitu peneliti terlebih dahulu menganalisis data kualitatif baru kemudian menganalisis data kuantitatif. Pengumpulan data dilakukan dengan mengadakan observasi, wawancara, dokumentasi dan angket untuk melengkapi data serta menggunakan data statistik sederhana untuk membantu dalam mengungkapkannya. Hasil penelitian menunjukan bahwa penerapan media pembelajaran bahasa arab berbasis android pada siswa kelas sepuluh MA Salafiyah kota cirebon sangat mudah dalam penerapanya sehingga dapat membangun semangat belajar dan siswa juga dapat berpartisipasi aktif dalam proses pembelajaran berlangsung. Disampng itu juga hasil angket yang disebar kepada kelas sepuluh tentang persepsi siswa terhadap penerapan media pembelajaran bahasa arab berbasis android menunjukan hasil yang sangat baik dengan nilai presentase $83 \%$. Ini merupakan hal yang positif dan perlu ditingkatkan oleh pendidik guna tercapainya tujuan pendidikan di MA Salafiyah kota cirebon.
\end{abstract}

Kata Kunci: Media Android, Pembelajaran Bahasa Arab, Madrasah Aliyah Salafiyah Kota Cirebon

\begin{abstract}
The study aims to describe the process of applying the android arabic-based media of education in the tenth class of cirebon city salafiyah and the student's perception of the application of the android based Arabic learning media. The basis of this study is that learning that USES technological media has significant impact on learning. The current android device is very close to the lives of students, apart from a communication function, an android device is also highly likely to be developed into an innovative and interactive media of learning that
\end{abstract}


students benefit. The study is a combination of mixed compounds, that is, a research move by combining two approaches in research, that is, a qualitative and quantitative approach with design (squential exploratory) the researcher irst analyzes the qualitative data then analyzes the quantitative data. Data collection involves observation, interviews, documentation and angkets to supplement the data and using simple statistics to help in expressing it. Research shows that the application of the android arabian-based learning media to the tenth graders salafiyah city is so easy to implement and that students can actively participate in the learning process. The next addition was an installment to the tenth class on the student's perception of the application of android arabic-based media of learning, showing excellent results with an $83 \%$ percentage value. This is a positive and will need to be enhanced by educators to achieve the educational objective of cirebon.

Keywords: Android Media, Arabic Language Learning, MA Salafiyah Cirebon City

\section{ملخص}

يهدف هذه البحث إلى تحديد عملية تعلم اللغة العربية على أساس Android

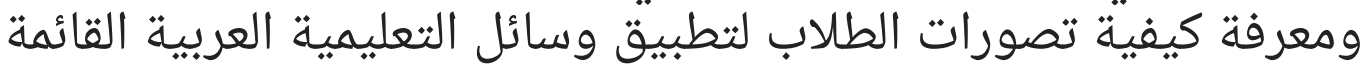

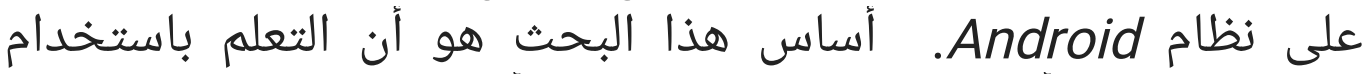

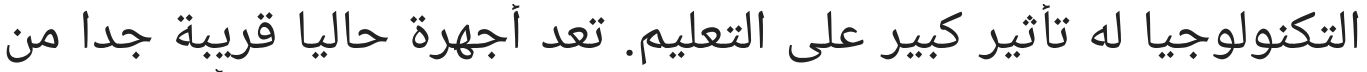

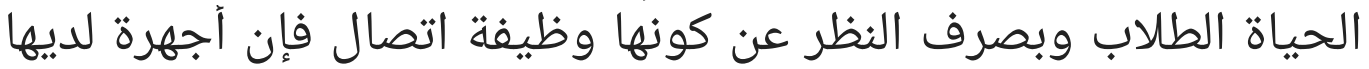

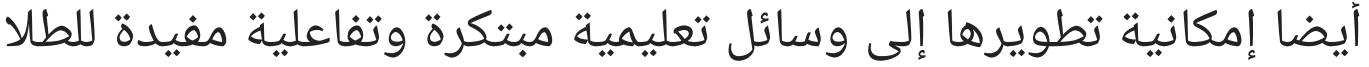

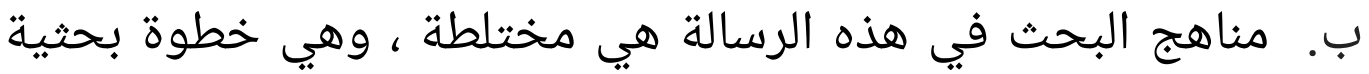

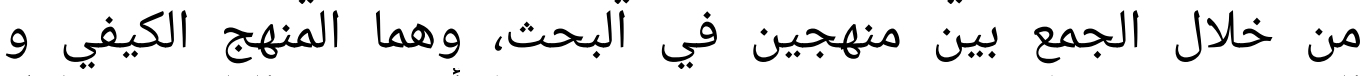

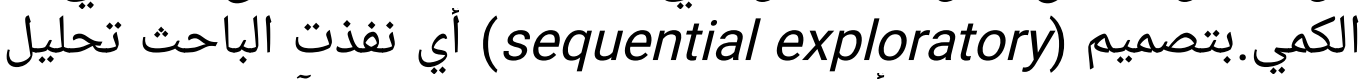

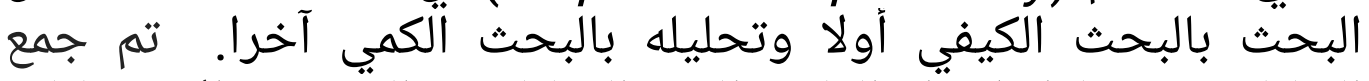

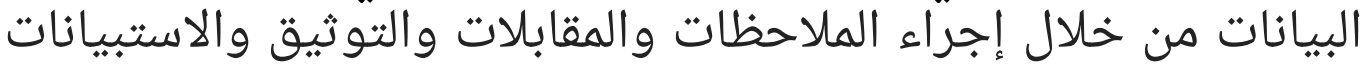

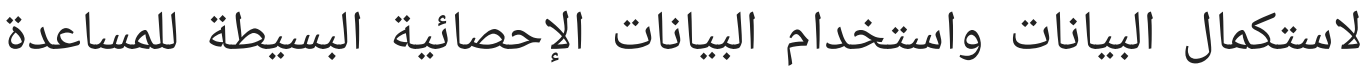
في التعبير عنها.

الكلمة الرئيسية : الوسيلة Android، التعلم اللغة العربية، المدرسة العالية السفية جيرابون الريسة

\section{Pendahuluan}

Media adalah alat yang digunakan sebagai perantara komunikasi antara guru dan murid dalam rangka lebih mengefektifkan komunikasi dan interaksi antara guru dan siswa dalam proses pendidikan pengajaran 
di sekolah. ${ }^{1}$ Media belajar mempunyai peran yang dapat meningkatkan kegiatan belajar mengajar (KBM) seperti dapat mengatasi suatu masalah keterbatasan ruang kelas. Media belajar tidak selalu disediakan dalam ruang kelas. Selain memudahkan siswa dalam memahami materi, penggunaan media dalam kegiatan belajar mengajar juga dapat bermanfaat bagi guru yang dapat menyajikan bahan pelajaran yang bersifak abstrak menjadi kongkret sehingga dapat dipahami oleh siswa.

Kedudukan media pembelajaran memiliki peran yang penting karena dalam kegiatan tersebut apabila materi atau bahan yang kurang jelas ketika disampaikan, dapat dibantu dengan menghadirkan media sebagai penunjang. Dengan bantuan media dalam proses pembelajaran ini dapat membuat peserta didik tidak jenuh dalam mengikuti pelajaran sehingga hal ini siswa dapat termotivasi dan mempermudah dalam menerima materi pelajaran. ${ }^{3}$

Dengan adanya media pembelajaran harapannya proses belajar mengajar dapat berlangsung secara maksimal dan sempurna sehingga tujuan dari proses belajar mengajar tersampaikan. Media pembelajaran juga sebagai sarana untuk meningkatkan proses belajar mengajar yang sedang berlangsung, karena media pembelajaran tidak hanya menampilkan tulisan ataupun gambar namun dengan suara yang dapat memperjelas materi yang akan disampaikan. ${ }^{4}$ Banyaknya bentuk media pembelajaran, maka guru harus kreatif dan pandai memilih media pembelajaran dengan baik dan benar. Sehingga media pembelajaran yang dipakai untuk proses pembelajaran tersebut dapat digunakan dengan tepat dan sesuai dengan tujuan pembelajaran.

Penting bagi para guru untuk menentukan media apakah yang akan digunakan dalam proses belajar, hal ini dikarenakan media yang sesuai pastilah akan lebih menarik minat para siswa yang mana dari waktu ke waktu memiliki respon yang bebeda apabila digunakan suatu media tertentu. Namun penggunaan media yang kurang tepat dan tidak sesuai dengan perkembangan zaman saat ini akan dapat menimbulkan anggapan dari siswa bahwa guru yang menggunakannya belum mampu mengikuti perkembangan yang ada. ${ }^{5}$

${ }^{1}$ Umar, Media Pendidikan, Jurnal Tarbawiyah Vol.10, No.2, (2013). Hal. 8.

2 Wina Sanjaya, Media Komunikasi Pembelajaran. (Jakarta: Kencana Prenada, 2012). Hal. 72.

3 Joko Kuswanto dan Ferri Radiansah, Media Pembelajaran Berbasis Android pada Mata Pelajaran Sistem Oprasi Jaringan. Media Infotama Vol.14, No.1, (2018). Hal. 15-20.

${ }^{4}$ Sitjipto Bambang \& Cecep Kustandi, Media Pembelajaran. (Bogor: Ghalia indonesia, 2011)

5 Edi Ismanto, Melly Novalia \& Pratama Benny Herlandy, Pemanfaatan Smartphone Android Sebagai Media Pembelajaran Bagi Guru SMA Negeri 2 Kota 
Penggunaan media teknologi pada pembelajaran memberikan pengaruh yang cukup signifikan terhadap proses pembelajaran. Perangkat android saat ini sangat dekat dengan kehidupan siswa, selain sebagai fungsi komunikasi, perangkat android juga sangat berpotensi dikembangkan menjadi media pembelajaran inovatif dan interaktif yang bermanfaat bagi siswa. Teknologi yang terintegrasi pada pembelajaran merupakan salah satu strategi pencapaian tujuan pembelajaran karena teknologi bukan lagi sebagai hal yang baru. Hal ini sesuai apa yang disampaikan (Ikhsan, Lubis, Sholihah, Sugiyarto, \& Jaslin, 2015) bahwa penggunaan perangkat mobile (smartphone, PDA atau tablet) sudah tidak asing lagi dikalangan peserta didik. Kebanyakan peserta didik SMA/MA sudah memiliki smartphone yang memiliki fitur yang lebih up to date. Smartphone yang menjadi tren masa kini yang berkembang sangat cepat adalah android. penggunaan android sebagai system operasi pendukung yang digunakan di Indonesia berkembang mencapai $57,13 \%{ }^{6}$

Perkembangan smartphone mengalami peningkatan pengguna yang sangat pesat, di tahun 2015 telah diperkirakan terdapat lebih dari 55 juta orang pengguna smartphone dengan total presentasi $37,1 \%$. Selanjutnya pada tahun 2016 diperkirakan terdapat 65,2 juta pengguna lalu pada tahun 2017 diperkirakan terdapat 74,9 juta orang pengguna hingga pada tahun 2019 diperkirakan pengguna smartphone di Indonesia mencapai 92 juta orang pengguna. ${ }^{7}$.

Berdasarkan hasil riset menunjukkan bahwa Indonesia berada diperingkat ketiga dalam daftar pengguna smartphone terbesar di Asia pasifik dengan jumlah pengguna $83,18 \%$ juta pada tahun 2017. Pengguna tersebut terdiri dari berbagai kalangan termasuk kalangan peserta didik yang masih duduk di bangku SMP sampai SMA. ${ }^{8}$

MA Salafiyyah Kota Cirebon, merupakan salah satu Madrasah Aliyah Swasta yang ada di Kota Cirebon, Provinsi Jawa Barat. MA Salafiyyah Kota Cirebon merupakan sekolah swasta yang memiliki akreditasi A dan berdiri dibawah yayasan Pendidikan Islam Salafiyah yang berdiri pada tahun 1982. Dalam proses pembelajaran di MA Salafiyyah Kota Cirebon ini sudah menggunakan teknologi sebagai media pembelajaran. Hal ini dibuktikan dengan adanya fasilistas yang

Pekanbaru, Jurnal Untukmu Negeri Vol. 01, No.01, (2017). Hal. 42-47.

6 Ikhsan, Isma Ramadhani Lubis dkk. Pengembangan Media Mobile Learning Chemondro Berbasis Android Sebagai Suplemen Belajar Siswa SMA, (Surakata: FKIP Universitas Negeri Yogyakarta 2015). Hal. 468-477.

${ }^{7}$ Andi Puspo Heriyanto, Mobile Phone Forensics: Theory: Mobile Phone Forensics and Security Series, (Yogyakarta : C.V Andi Offset 2016). Hal. 96.

8 Najwa Chadeja, Ara Fahana Salsabla \& Nazula Nur Azizah, Penggunaan Smartphone pada Kontruksi Belajar Siswa MTs Negeri 7 Model Jakarta, Al-Izzah:Jurnal Hasil-Hasil Penelitian, Vol.13, No.02, (2017). Hal. 240 
menunjang pembelajaran yaitu satu ruangan laboratorium komputer dengan luas $16 \mathrm{~cm}^{2}$ dalam kondisi yang baik.sehingga siswa maupun guru dapat mengakses informasi maupun materi pembelajaran dengan mudah. Dan ada beberapa guru yang sudah menggunakan media-media teknologi sebagai pembelajarannya.

Berdasarkan wawancara peneliti pada tanggal 5 september 2018 dengan guru pengampu bahasa arab di kelas sepuluh yang bernama Rahmat Hidayat S.Pd.I, bahwa sebelum menggunakan media android dalam proses pembelajaran, guru menggunakan media cetak seperti LKS, buku panduan dan penyampainyan materinya hanya dengan menggunakan metode ceramah. Hal tersebut belum dapat meningkatkan hasil belajar siswa sehingga siswa menjadi bosan, jenuh dan kurang semangat dalam belajar bahasa arab. Namun setelah guru mencoba untuk melakukan inovasi dalam menggunakan media pembelajaran dengan memanfaatkan teknologi informasi berupa smartphone dengan sistem operasi android dapat membuat siswa lebih aktif, dan semangat dalam proses pembelajaran bahasa arab. Hasil dari pembelajaran tersebut menunjukkan perolehan nilai sebesar $84 \%$ di atas KKM (75) dan $16 \%$ di bawah KKM (75). Dengan hasil tersebut bahwa penerapan media pembelajaran berbasis android dapat mencapai prestasi yang diharapkan.

Berdasarkan penemuan peneliti yaitu penerapan media pembelajaran bahasa arab berbasis android di kelas sepuluh yang telah dilakukan oleh seorang guru bahasa arab di MA Salafiyah Kota Cirebon. Hal tersebut yang melatarbelakangi penelitian ini. Peneliti akan menggambarkan bagaimana proses penerapan media pembelajaran bahasa arab berbasis android yang dilakukan oleh Bapak Rahmat Hidayat selaku guru bahasa arab di MA Salaiyah Kota Cirebon dan persepsi siswa kelas Sepuluh terhadap penerapan media pembelajaran bahasa arab berbasis androd tersebut.

\section{Metode Penelitian}

Penelitian ini merupakan penelitian kombinasi (mixed methods), yaitu langkah penelitian dengan menggabungkan dua bentuk pendekatan dalam penelitian, yaitu pendekatan kualitatif dan kuantitatif. Mixed methods menghasilkan fakta yang lebih komprehensif dalam meneliti masalah penelitian, karena penelitian ini memiliki kebebasan untuk menggunakan semua alata pengumpul data sesuai dengan jenis data yang dibutuhkan. Sedangkan kulitatif dan kuantitatif hanya terbatas pada jenis alat pengumpul data tertentu saja.

Mixed Methods adalah suatu metode penelitian yang mengkombinasikan atau menggabungkan antara metode kuantitatif dan metode kualitatif untuk digunakan secara bersama-sama dalam suatu kegiatan penelitian sehingga diperoleh data yang lebih komprehensif, 
valid, reliabel, dan objektif. ${ }^{9}$

Penelitian kombinasi (mixed methods) memiliki beberapa desain penelitian di dalamnya. Namun dalam penelitian ini peneliti menggunakan desain model urutan penemuan (sequential exploratory) dimana yang pertama peneliti melaksanakan tahap kajian penelitian kualitatif kemudian disambung dengan tahap penelitian kuantitatif. Dalam hal ini penelitian kuantitatif digunakan untuk memperkuat penelitian kualitatif.

Dalam penelitian ini peneliti menggunakan jenis data dari sumber primer dan sumber sekunder. Data primer secara khusus dikumpulkan oleh peneliti untuk menjawab pertanyan penelitian. Sumber primer, peneliti dapatkan dari Bapak Rahmat Hidayat selaku Guru bahasa arab dan siswa kelas sepuluh MA Salafiyah Kota Cirebon. Sedangkan data primer peneliti dapatkan dari dokumentasi, catatan-catatan tertulis di lapangan dan membaca literatur-literatur yang dapat menunjang penelitian, yaitu literatur-literatur yang berhubungan dengan penelitian ini, seperti halnya jurnal, buku dan artikel.

Teknik pengumpulan data yang digunakan dalam penelitian ini yaitu obesrvasi, dokumentasi, wawancara dan angket. Pada Teknik observasi yang dilakukan oleh peneliti adalah teknik observasi nonpartisipan (nonparticipatory observation). Pelaksanaan observasi ini peneliti tidak ikut terlibat langsung pada aktifitas yang sedang diamati di tempat penelitian. Adapun teknik observasi digunakan untuk memperoleh data mengenai proses pembelajaran bahasa Arab berbasis android. Sedangkan dokumentasi digunakan untuk memperoleh data mengenai gambaran umum MA Salafiyah kota Cirebon, yaitu dari mulai sejarah berdirinya, letak geografis, visi, misi dan tujuan, pogram, sarana dan prasarana dan lani-lain

Metode wawancara digunakan oleh peneliti dengan bapak Rahmat Hidayat S.Pd sebagai guru bahasa arab MA Salafiyah Kota Cirebon untuk memperoleh data mengenai proses penerapan media pembelajaran bahasa arab berbasis android. Sedangkan kuesioner merupakan teknik pengumpulan data yang dilakukan dengan cara memberi seperangkat pertanyaan atau pernyataan tertulis kepada responden untuk dijawabnya. ${ }^{10}$ Kuesioner adalah sejumlah pertanyaan tertulis yang digunakan untuk memperoleh informasi dari responden dalam arti laporan tentang pribdinya atau hal yang ia ketahui. ${ }^{11}$

Penelitian ini menggunakan instrumen angket skala persepsi dengan model likert. Skala likert digunakan untuk mengukur sikap,

\footnotetext{
${ }^{9}$ Sugiyono, Metode Penelitian dan Pengembangan, (Bandung: PT.Alpabeta, 2017).
}

${ }^{10}$ Sugiyono, Metode Penelitian Pendidikan (Pendekatan Kuantitatif, Kualitatif dan $R \& D)$, (Bandung: Alpabeta 2014).

${ }_{11}$ Suharsimi Arikunto, Prosedur Penelitian : Suatu Pendekatan Praktik, (Jakarta: Rineka Cipta 2013) 
pendapat, persepsi seseorang atau sekelompok orang tentang fenomena sosial. Dengan skala likert, variabel yang akan diukur dijabarkan menjadi indikator variabel. Selanjutnya indikator tersebut dijadikan titik tolak untuk menyusun item-item instrument yang dapat berupa pertanyaan atau pernyataan. Angket yang digunakan disusun berdasarkan persepsi siswa terhadap penerapan media pembelajaran bahasa arab berbasis android yang berjumlah 16 pernyataan.

Adapun kriteria media pembelajaran yang baik adalah sebagai berikut: 1) Sesuai dengan tujuan, 2) Praktis, luwes, bertahan, 3)mampu dan terampil menggunakan, 4) keadaan peserta didik, 5) ketersidiaan. ${ }^{12}$ Dengan mengacu pada hal tersebut maka dibuatlah kisi-kisi instrument penelitian sebagai berikut:

\begin{tabular}{|c|l|c|c|}
\hline \multicolumn{1}{|c|}{ Aspek } & \multicolumn{1}{|c|}{ Indikator } & $\begin{array}{c}\text { Nomor } \\
\text { Butir }\end{array}$ & $\begin{array}{c}\text { Jumlah } \\
\text { Butir }\end{array}$ \\
\hline \multirow{1}{*}{$\begin{array}{l}\text { Kesesuaian } \\
\text { dengan tujuan }\end{array}$} & $\begin{array}{l}\text { Pemilihan tujuan dan } \\
\text { indikator } \\
\text { pembelajaran } \\
\text { memudahkan siswa } \\
\text { dalam memahami } \\
\text { materi }\end{array}$ & 1 & 1 \\
\cline { 2 - 4 } & $\begin{array}{l}\text { Kesesuaian antara } \\
\text { materi dan evaluasi }\end{array}$ & 2 & 1 \\
\cline { 2 - 4 } & $\begin{array}{l}\text { Penyajian materi } \\
\text { memungkinkan } \\
\text { siswa untuk belajar } \\
\text { mandiri }\end{array}$ & 3 & 1 \\
\cline { 2 - 4 } & $\begin{array}{l}\text { Materi terorganisasi } \\
\text { dengan baik }\end{array}$ & 4 & 1 \\
\cline { 2 - 4 } & $\begin{array}{l}\text { Kesesuaian teks, } \\
\text { audio, gambar dan } \\
\text { video yang disajikan } \\
\text { dalam media } \\
\text { pembelajaran }\end{array}$ & $5,6,7,8$ & 4 \\
\hline
\end{tabular}

${ }^{12}$ Azhar Arsyad, Media Pembelajaran, (Jakarta: Rajawal Press 2013), Hal.74 


\begin{tabular}{|c|c|c|c|}
\hline \multirow[t]{2}{*}{$\begin{array}{l}\text { Praktis, luwes, } \\
\text { bertahan }\end{array}$} & $\begin{array}{l}\text { Media dapat } \\
\text { digunakan kapan } \\
\text { saja dan dimana saja } \\
\text { oleh siswa }\end{array}$ & 9 & 1 \\
\hline & $\begin{array}{l}\text { Media Dapat } \\
\text { digunakan secara } \\
\text { terus-menerus }\end{array}$ & 10 & 1 \\
\hline $\begin{array}{l}\text { Mampu dan } \\
\text { terampil } \\
\text { menggunakan }\end{array}$ & $\begin{array}{l}\text { Kemudahan dan } \\
\text { kesederhanaan } \\
\text { dalam pengoprasian }\end{array}$ & 11,12 & 2 \\
\hline $\begin{array}{l}\text { Keadaan } \\
\text { peserta didik }\end{array}$ & $\begin{array}{l}\text { Media pembelajaran } \\
\text { dapat meningkatkan } \\
\text { semangat belajar } \\
\text { siswa }\end{array}$ & $13,14,15$ & 3 \\
\hline Ketersidiaan. & $\begin{array}{l}\text { Media dapat diakses } \\
\text { dengan mudah }\end{array}$ & 16 & 1 \\
\hline \multicolumn{3}{|c|}{ Total } & 16 \\
\hline
\end{tabular}

Dalam penelitian ini peneliti menggunakan dua proses analisis data, yang pertama analisis data kualitatif kemudian yang kedua analisis data kuantitatif. Untuk menganalisis data kualitatif peneliti menggunakan analisis data yang bukan berupa angka tetapi data yang berupa keterangan-keterangan. Metode ini digunakan untuk menyajikan dan menganalisis data serta memberi kesimpulan yang sesuai dengan fakta yang terjadi pada lokasi penelitian, dengan menggunakan analisis model Miles dan Huberman yang meliputi langkah-langkah sebagai berikut: redukusi data, penyajian data dan verifikasi data. setelah peneliti mendapatkan data, peneliti menganalisis data melalui reduksi data, peneliti memilih dan memfokuskan pada hal-hal yang penting yang berhubungan dengan penelitian ini. Setelah mereduksi data, peneliti kemudian melakukan penyajian data berupa uraian singkat, lalu langkah terakhir peneliti melakukan penarikan kesimpulan dan verifikasi. 
Analisis data kuantitatif yang peneliti gunakan dalam penelitian ini adalah analisis statistik, hasil analisis nantinya akan disajikan dalam bentuk angka-angka yang kemudian dijelaskan dan diinterpretasikan dalam bentuk uraian. Analisis kuantitatif digunakan untuk mengetahui respon siswa terhadap penerapan media pembelajaran bahasa arab berbasis android yaitu dengan penyebaran angket atau kuesioner kepada siswa.

Dalam analisis data kuantitatif, peneliti menganalisis hasil penyebaran angket kepada siswa. Pada penelitian ini, angket respons siswa yang observasi digunakan penilaian adalah skala likert yang terdiri dari pernyataan positif dan pernyataan negatif.

Langkah-langkah dalam menganalisis hasil angket respon siswa adalah sebagai berikut:

1) Mengelompokkan siswa yang memilih sangat setuju, setuju, raguragu, tidak setuju, dan sangat tidak setuju.

2) Data yang dianalisis secara kuantitatif adalah data yang diperoleh angket. Angket minat siswa dihitung dengan menggunakan rumus sebagai berikut ${ }^{13}$

$$
p=\frac{f}{n} \times 100 \%
$$

Keterangan:

$p=$ persentase alternatif jawaban

$f=$ jumlah yang mengisi alternatif jawaban

$n=$ jumlah sampel

Setelah dihitung respons siswa yang berasal dari angket dianalisis dengan menggunakan kriteria sebagai berikut:

Klasifikasi Angket Respons Siswa

\begin{tabular}{|c|c|c|}
\hline No & $\begin{array}{c}\text { Nilai Angket } \\
\text { Respon }\end{array}$ & Interpretasi \\
\hline 1 & $0 \%-20 \%$ & Sangat Lemah \\
\hline 2 & $21 \%-40 \%$ & Lemah \\
\hline 3 & $41 \%-60 \%$ & Kuat \\
\hline 4 & $61 \%-80 \%$ & Sangat Kuat \\
\hline 5 & $81 \%-100 \%$ & \\
\hline
\end{tabular}

${ }^{13}$ Yudhanega Lestari, Penelitian Pendidikan Matematika, (Bandung: PT.Refika Aditama 2015) 


\section{Pengertian Media Pembelajaran}

Media pembelajaran adalah segala sesuatu baik berupa fisik maupun teknis dalam proses pembelajaran yang dapat membantu guru untuk mempermudah dalam menyampaikan materi pelajaran kepada siswa sehingga memudahkan pencapaian tujuan pembelajaran. ${ }^{14}$

Peran media pembelajaran dalam proses belajar mengajar ini sangatlah penting dilaksanakan oleh para guru saat ini. Karena peranan media pembelajaran itu sendiri adalah untuk menyalurkan pesan pengirim kepada penerima dan melalui media pembelajaran juga dapat membantu memperjelas sesuatu yang disampaikan oleh guru. Guru harus menghadirkan suasana pembelajaran yang menyenangkan agar hasil yang diperoleh dari proses pembelajaran akan lebih efektif dan optimal.

\section{Pengertian Android}

Menurut Jazi Eko Istiyanto (2013) mengatakan bahwa Android merupakan suatu sistem software stack yang terhubung dan terdistribusi secara open soure (terbuka) yang terdiri dari sistem operasi, middleware, dan aplikasi dasar (key application). Sistem operasi android dirancang untuk perangkat mobile dan merupakan sistem operasi turunan dari sistem operasi karnel linux, sehingga sistem operasi android sangat mirip dengan sistem operasi linux ${ }^{15}$

Android merupakan sebuah sistem operasi berbasis linux yang didesain khusus untuk perangkat bergerak seperti smartphone dan tablet. Android mempunyai jumlah pengguna paling besar karena mudah digunakan dan memiliki beberapa keunggulan dalam sistem operasinya. Android juga memiliki berbagai fitur yang dapat dimanfaatkan untuk menunjang dalam penggunaannya sebagai mobile learning. ${ }^{16}$

Dengan menggunakan media android dapan menciptakan suasana yang menyenangkan. Pemakaian android dalam kegiatan pembelajaran yaitu:

a. Untuk tujuan kognitif

Android mengajarkan konsep-konsep sederhana dan menyenangkan dengan cara penggunaan visual dan audio

14 Stefii Adam dkk, Pemanfaatan Media Pembelajaran Berbasis Teknologi Informasi bagi Siswa Kelas X SMA Ananda Batam, CBIS Journal, Vol.03 No.01, 2015. Hal. 79.

15 Jazi Eko Istiyanto, Pemograman Smart Phone Menggunakan SDK Android dan Hacking Androi, (Yogyakarta: Graha Ilmu, 2013). Hal. 19.

${ }^{16}$ Lukni Maulana, Pengembangan Media Pembelajaran Berbasis Mobile Learning dengan Platorm Android Materi Keselamatan Kerja dan Lingkungan Hidup (K3LH) pada Program Studi Ketenagalistrikan untuk Siswa Sekolah Menengah Kejuruan, E-Jurnal Universitas Negeri Yogyakarta, Vol.07, No.02, 2017. Hal. 188. 
yang dianimaskan. Sehingga cocok untuk kegiatan pembelajaran mandiri.

b. Untuk tujuan psikomotorik

Dengan bentuk pembelajaran yang dikemas dalam bentuk animasi sangat bagus untuk menciptakan kondisi dunia pendidikan

c. Untuk tujuan afektif

Bila program didesain tepat dengan memberikan potongan clip suara atau video yang isinya menggugah perasaan, pembelajaran sikap afektif dapat dilakukan dengan media android dengan cara yang menyenangkan.

\section{Pengertian Mobile Learning}

Mobile learning merupakan alternatif proses pembelajaran saat ini. Hal ini karena dengan mobile learning dapat dilakukan dimana saja dan kapan saja. Sifat dari mobile learning yang dapat dilakukan kapan saja dan dimana saja tentu tidak dapat berdiri sendiri oleh karena itu mobile learning perlu adanya bantuan tambahan dari jaringan seluler. Penggunaan yang mudah membuat mobile learning dapat digunakan oleh siapa saja tanpa terkecuali. ${ }^{17}$

Mobile learning merupakan sebuah proses pembelajaran yang memanfaatkan teknologi dan perangkat Mobile. Pemakaian Mobile learning dapat dibantu dengan telephone seluler, laptop atau tablet. ${ }^{18}$ Proses pembelajaran akan lebih mudah dengan bantuan Mobile learning. Karena, dengan Mobile learning dapat diakses dimana saja kapan saja serta oleh siapa saja.

Mobile learning ini dapat digunakan dengan mudah dan tidak menyulitkan siswa akan menambah daya tarik dan keingintahuan siswa untuk mengenal tentang mobile learning berbasis android . dengan mobile learning berbasis android ini siswa dapat berinteraksi dalam pembelajaran di dalam maupun diluar kelas sehngga belajarnya akan lebih efektif dan efisien pada materi pembelajaran bahasa arab yang banyak menggunakan gambar, audio dan video yang dapat dibantu dengan menggunakan mobile learning ini.

\section{Penerapan Media Pembelajaran Bahasa Arab Berbasis Android}

1. Guru menyampaikan kepada siswa bahwa pada pertemuan kali ini akan belajar bahasa arab dengan menggunakan media pembelajaran berbasis android dengan tema هوَايَيَّ الطَلا

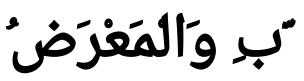

${ }^{17}$ Deni Drmawan, Teknologi Pembelajaran, (Bandung: P.T. Remaja Rosdakarya, 2012). Hal. 15.

${ }_{18}$ Ariesto Hadi Sutopo, Teknologi Informasi dan Komunikasi dalam Pendidikan, (Yogyakarta: Graha Ilmu, 2012) 
2. Guru menyampaikan kepada siswa untuk membuka handphone masing-masing

3. Guru mengirim file aplikasi media pembelajaran bahasa arab berbaiss android kepada siswa

4. Setelah siswa menerima file aplikasi tersebut kemudian siswa meng-instal nya di handphone siswa masing-masing

5. Guru menyampaikan kepada siswa untuk membuka aplikasi media pembelajaran bahasa arab berbaiss android

6. Guru menyampaikan kepada siswa untuk menggunakan media tersebut sesuai dengan petunjuk yang ada pada media pembelajaran bahasa arab berbaiss android

7. Tampilan awal pada aplikasi media pembelajaran bahasa arab berbasis android

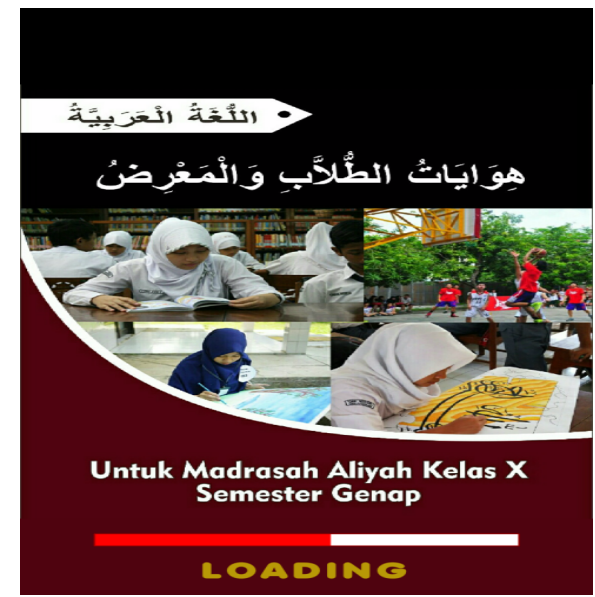

Gambar 1. Tampilan menu awal

8. Menu utama pada media pembelajaran bahasa arab berbasis android 


\section{MENU UTAmA}

Indikator

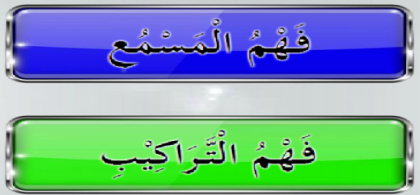

Evaluasi

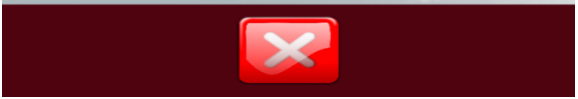

gambar 2. Tampilan menu utama

9. Indikator materi maharotul istima' dan tarokib pada media pembelajaran bahasa arab berbasis android

\section{inatikator}

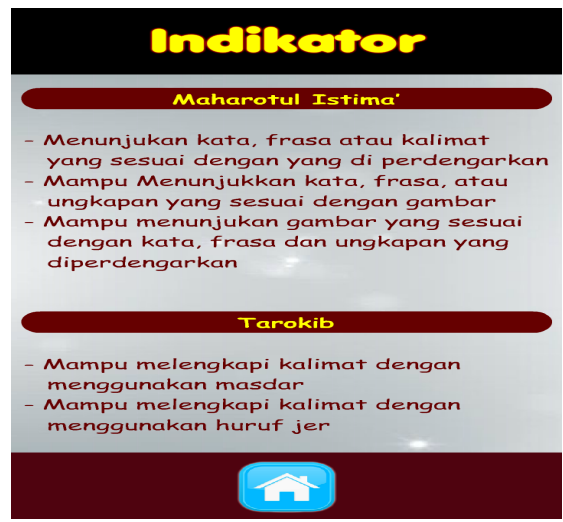

gambar 3. Tampilan menu indikator

10. Berikut ini adalah materi pembelajaran maharotul istima' 


\section{Maharotul Istima"}
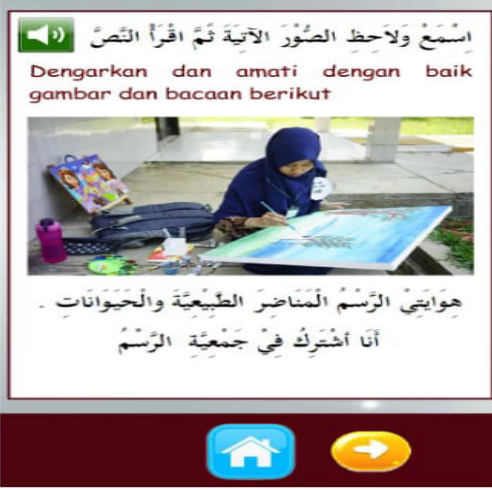

\section{Maharotul Istima"}

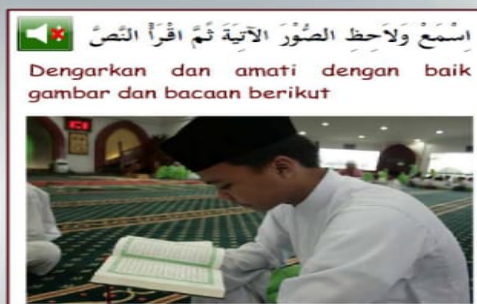

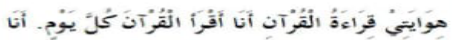

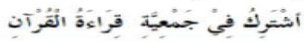

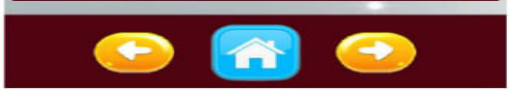

\section{Maharotul Istima"}

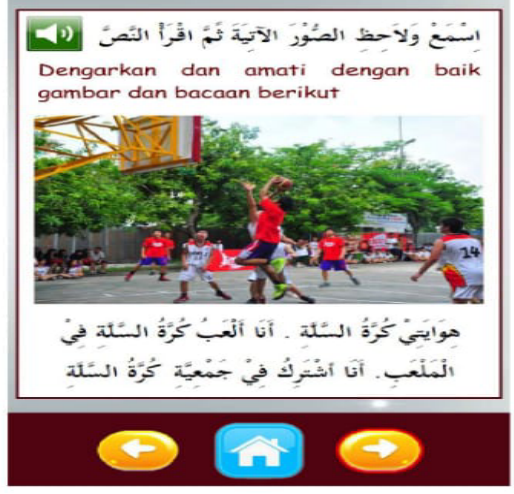

\section{Maharotul Istima"}

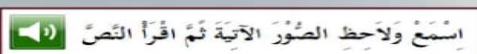

Dengarkan dan amati dengan baik gambar dan bacaan berikut

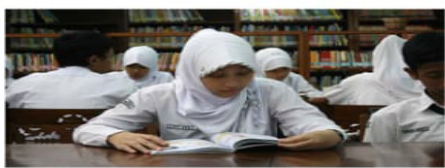

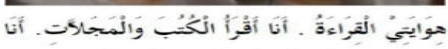

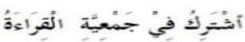

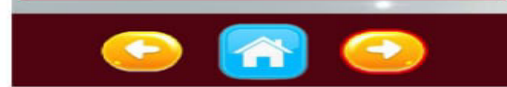

Gambar 4. Tampilan Menu Materi Maharotul Istima' 


\section{Maharotul Istima"}
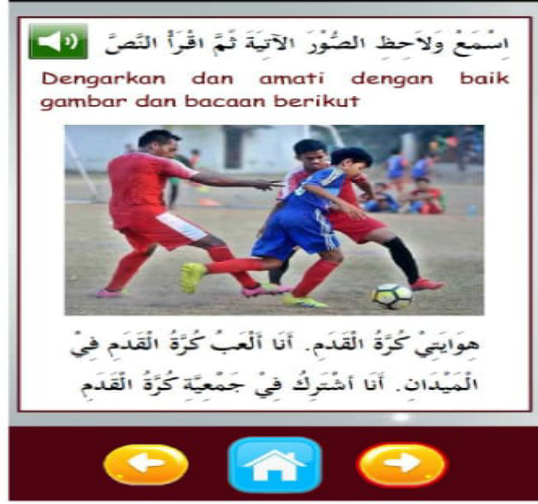

\section{Maharotul Istima"}

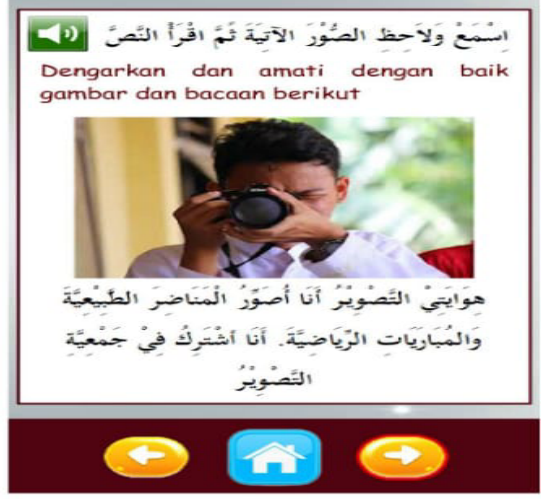

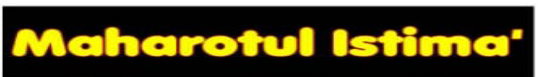

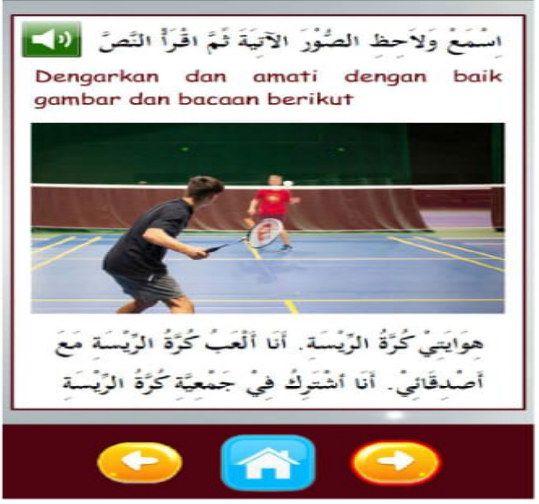

\section{Maharotel Istima"}

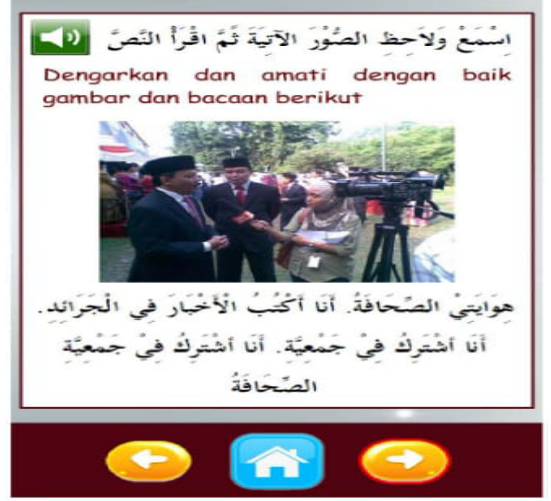

Gambar 5. Tampilan Menu Materi Maharotul Istima' 11. Setelah siswa mempelajari semua materi kemudia siswa akan mengerjakan evaluasi yang ada pada aplikasi media android tersebut. 


\section{Maharotel Istima"}

\begin{tabular}{|c|}
\hline Evaluasi \\
\hline $\begin{array}{l}\text { 1. Evaluasi ini terdiri dari } 10 \text { soal } \\
\text { pilihan ganda dengan masing-masing } \\
4 \text { pilihan jawaban. } \\
\text { 2. Jawablah soal dengan memilih salah } \\
\text { satu pilihan jawaban yang paling } \\
\text { tepat. } \\
\text { 3. Setiap jawaban benar bernilai } 10 \\
\text { poin, sedangkan jawaban salah tidak } \\
\text { mendapat nilai. } \\
\text { 4. Pada akhir evaluasi akan ditampilkan } \\
\text { jumlah jawaban benar, jumlah } \\
\text { jawaban salah, dan total nilai yang } \\
\text { diperoleh. }\end{array}$ \\
\hline MULAI \\
\hline
\end{tabular}

Gambar 6. Tampilan Menu Evaluasi

12. Siswa mengerjakan soal evaluasi maharotul istima' yang berjumlah 10 soal
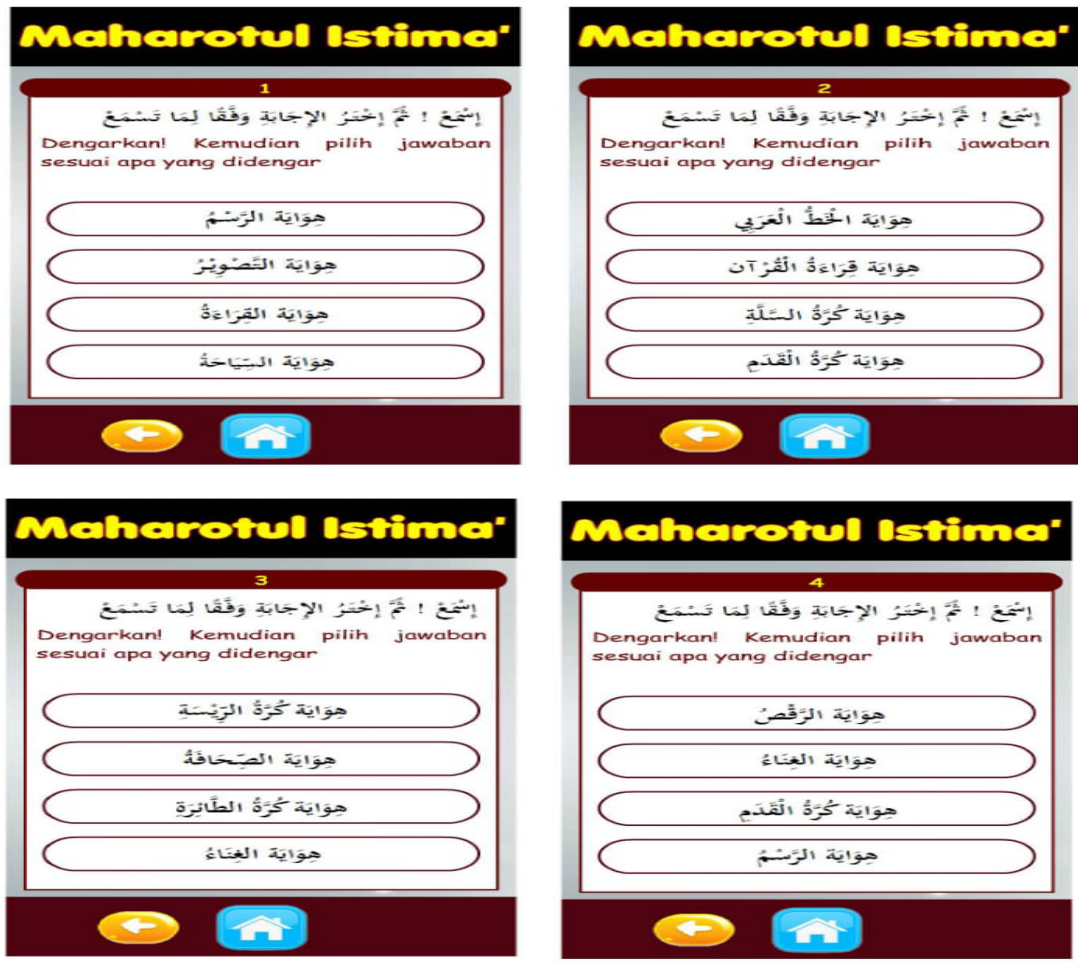

Gambar 7. Soal Evaluasi Maharorul Istima' 

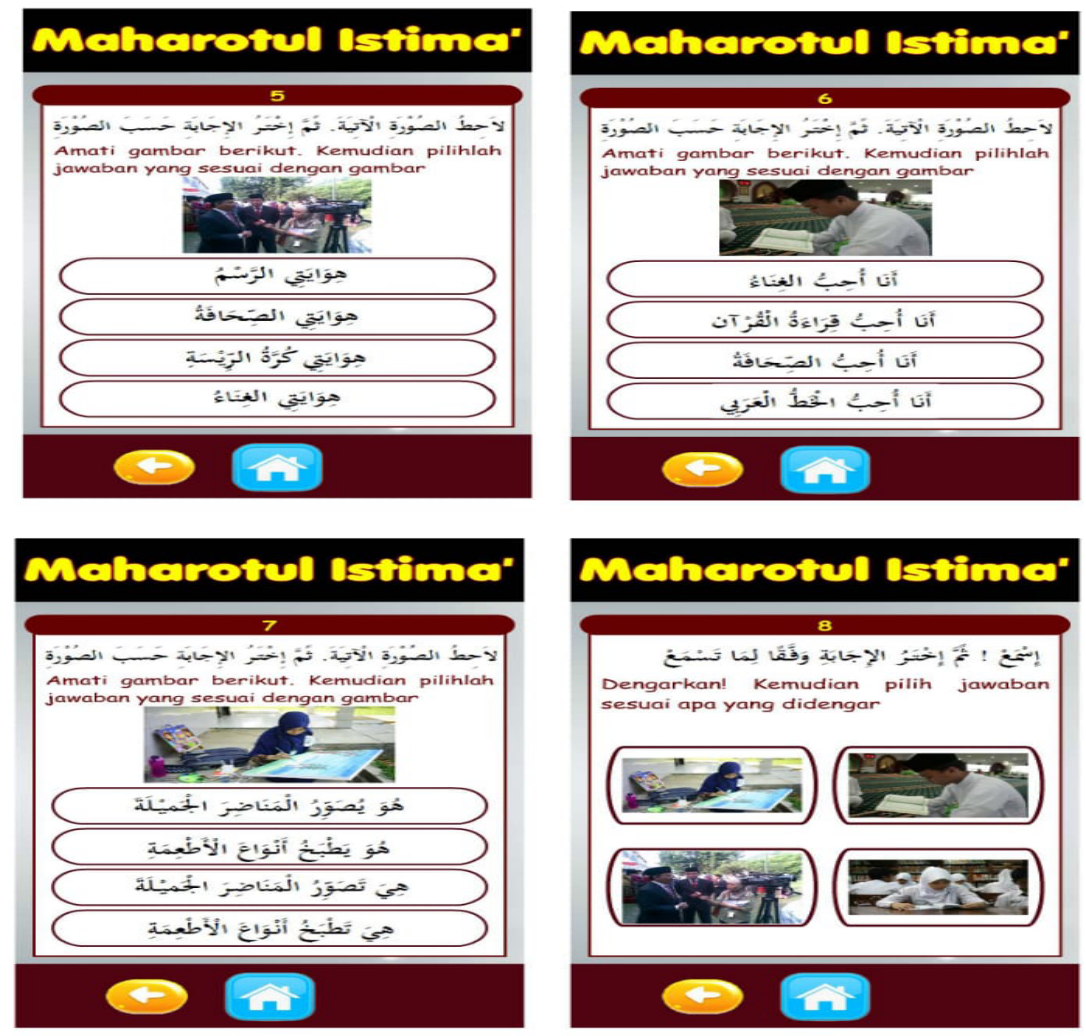

Gambar 8. Soal Evaluasi Maharorul Istima'
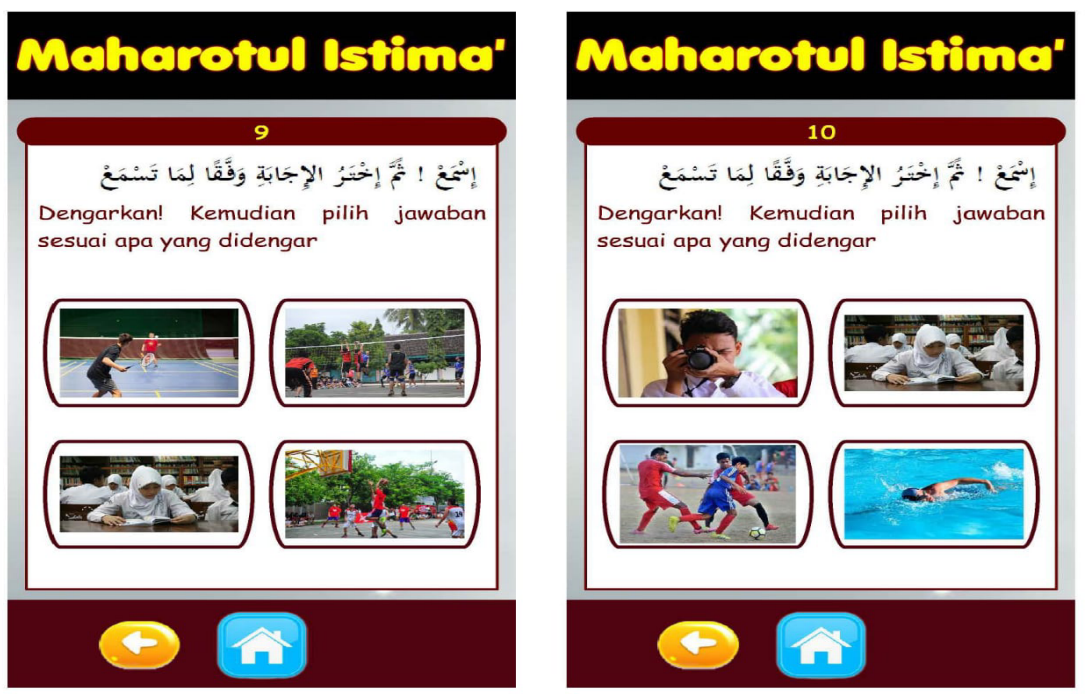

Gambar 9. Soal Evaluasi Maharorul Istima'

13. Setelah siswa menyelesaikan semua evaluasi maka akan muncul secara otomatis nilainya dalam aplikasi media pembelajaran bahasa arab berbasis android tersebut 


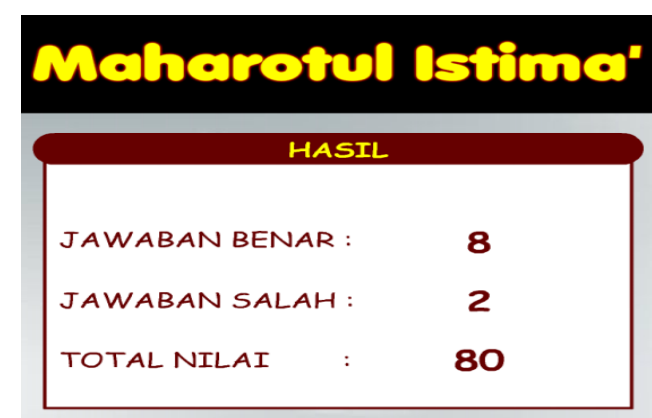

SELESAI

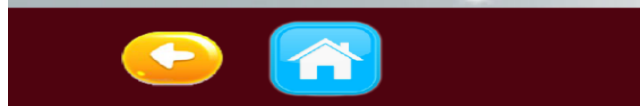

Gambar 10. Tampilan Menu Nilai Skor

Hasil Analisis Data Angket Kelas Sepuluh MA Salafiyah Kota Cirebon

\begin{tabular}{|c|c|c|c|c|c|c|c|c|c|c|c|c|}
\hline \multirow[t]{2}{*}{ No } & \multicolumn{2}{|c|}{ STS } & \multicolumn{2}{|c|}{ TS } & \multicolumn{2}{|c|}{ K } & \multicolumn{2}{|r|}{$S$} & \multicolumn{2}{|c|}{ SS } & \multicolumn{2}{|c|}{$\begin{array}{c}\text { Total } \\
\text { Frekuensi }\end{array}$} \\
\hline & $F$ & $\mathrm{P}(\%)$ & $F$ & $\mathrm{P}(\%)$ & $F$ & $\mathrm{P}(\%)$ & $F$ & $\mathrm{P}(\%)$ & $F$ & $\mathrm{P}(\%)$ & $F$ & $\mathrm{P}(\%)$ \\
\hline 1 & 0 & $0 \%$ & 0 & $0 \%$ & 0 & $0 \%$ & 4 & $24 \%$ & 13 & $76 \%$ & 17 & $100 \%$ \\
\hline 2 & 0 & $0 \%$ & 0 & $0 \%$ & 0 & $0 \%$ & 4 & $24 \%$ & 13 & $76 \%$ & 17 & $100 \%$ \\
\hline 3 & 0 & $0 \%$ & 0 & $0 \%$ & 1 & $6 \%$ & 13 & $76 \%$ & 3 & $18 \%$ & 17 & $100 \%$ \\
\hline 6 & 0 & $0 \%$ & 2 & $12 \%$ & 0 & $0 \%$ & 6 & $35 \%$ & 9 & $53 \%$ & 17 & $100 \%$ \\
\hline 7 & 0 & $0 \%$ & 1 & $6 \%$ & 0 & $0 \%$ & 11 & $65 \%$ & 5 & $29 \%$ & 17 & $100 \%$ \\
\hline 9 & 0 & $0 \%$ & 0 & $0 \%$ & 0 & $0 \%$ & 2 & $12 \%$ & 15 & $88 \%$ & 17 & $100 \%$ \\
\hline 11 & 0 & $0 \%$ & 0 & $0 \%$ & 0 & $0 \%$ & 7 & $41 \%$ & 10 & $59 \%$ & 17 & $100 \%$ \\
\hline 13 & 0 & $0 \%$ & 0 & $0 \%$ & 2 & $12 \%$ & 13 & $76 \%$ & 2 & $12 \%$ & 17 & $100 \%$ \\
\hline
\end{tabular}




\begin{tabular}{|c|c|c|c|c|c|c|c|c|c|c|c|c|}
\hline 14 & 0 & $0 \%$ & 0 & $0 \%$ & 0 & $0 \%$ & 15 & $88 \%$ & 2 & $12 \%$ & 17 & $100 \%$ \\
\hline 16 & 0 & $0 \%$ & 0 & $0 \%$ & 0 & $0 \%$ & 3 & $18 \%$ & 14 & $82 \%$ & 17 & $100 \%$ \\
\hline $\begin{array}{c}\text { Rata- } \\
\text { rata }\end{array}$ & 0 & $0 \%$ & 0, & $2 \%$ & 0,3 & $2 \%$ & 7,6 & $46 \%$ & 8,6 & $50 \%$ & 17,00 & $100 \%$ \\
\hline
\end{tabular}

Tabel 1. Rekapitulasi angket positif

Berdasarkan rekapitulasi angket positif pada tabel diatas, siswa kelas sepuluh MA Salafiyah Kota Cirebon yang berjumlah 17 siswa menjawab "Sangat Tidak Setuju" 0\%, "Tidak Setuju" 2\%, "Ragu-ragu" 2\%, "Setuju" 46\% dan "Sangat Setuju" 50\%.

\begin{tabular}{|c|c|c|c|c|c|c|c|c|c|c|c|c|}
\hline \multirow[t]{2}{*}{ No } & \multicolumn{2}{|c|}{ SS } & \multicolumn{2}{|r|}{$S$} & \multicolumn{2}{|r|}{$\mathrm{K}$} & \multicolumn{2}{|c|}{ TS } & \multicolumn{2}{|c|}{ STS } & \multicolumn{2}{|c|}{$\begin{array}{c}\text { Total } \\
\text { Frekuensi }\end{array}$} \\
\hline & $F$ & $\mathrm{P}(\%)$ & $F$ & $\mathrm{P}(\%)$ & $F$ & $\mathrm{P}(\%)$ & $F$ & $\mathrm{P}(\%)$ & $F$ & $\mathrm{P}(\%)$ & $F$ & $\mathrm{P}(\%)$ \\
\hline 4 & 0 & $0 \%$ & 2 & $12 \%$ & 6 & $35 \%$ & 9 & $53 \%$ & 0 & $0 \%$ & 17 & $100^{\circ}$ \\
\hline 5 & 1 & $6 \%$ & 0 & $0 \%$ & 6 & $35 \%$ & 10 & $59 \%$ & 0 & $0 \%$ & 17 & $100^{\circ}$ \\
\hline 8 & 0 & $0 \%$ & 1 & $6 \%$ & 5 & $29 \%$ & 10 & $59 \%$ & 1 & $6 \%$ & 17 & $100^{c}$ \\
\hline 10 & 1 & $6 \%$ & 0 & $0 \%$ & 1 & $6 \%$ & 2 & $12 \%$ & 13 & $76 \%$ & 17 & $100^{\circ}$ \\
\hline 12 & 0 & $0 \%$ & 0 & $0 \%$ & 0 & $0 \%$ & 9 & $53 \%$ & 8 & $47 \%$ & 17 & $100^{\circ}$ \\
\hline 15 & 0 & $0 \%$ & 1 & $6 \%$ & 2 & $12 \%$ & 12 & $70 \%$ & 2 & $12 \%$ & 17 & $100^{\circ}$ \\
\hline $\begin{array}{l}\text { Rata- } \\
\text { rata }\end{array}$ & 0,3 & $2 \%$ & $\begin{array}{l}0, \\
7\end{array}$ & $3 \%$ & 3,3 & $20 \%$ & 8,6 & $51 \%$ & 4,0 & $24 \%$ & 17,00 & $100^{\circ}$ \\
\hline
\end{tabular}

Tabel 2. Rekapitulasi Angket Negatif

Berdasarkan rekapitulasi angket negatif pada tabel diatas, siswa kelas sepuluh MA Salafiyah Kota Cirebon yang berjumlah 17 siswa menjawab "Sangat Setuju" 2\%, "Setuju" 3\%, "Ragu-ragu" 20\%, "Tidak Setuju" 51\%, "Sangat Tidak Setuju" 24\%,

\section{Ranting Scala dan Kategori Angket}

\begin{tabular}{|l|l|l|l|l|l|c|}
\hline No & 1 & 2 & 3 & 4 & 5 & Total \\
Frekuensi
\end{tabular}




\begin{tabular}{|c|c|c|c|c|c|c|c|c|c|c|c|r}
\hline & $F$ & Skor & $F$ & Skor & $F$ & Skor & $F$ & Skor & $F$ & Skor & $F$ & Sko \\
\hline $\mathbf{1}$ & 0 & 0 & 0 & 0 & 0 & 0 & 4 & 16 & 13 & 65 & 17 & 81 \\
\hline $\mathbf{2}$ & 0 & 0 & 0 & 0 & 0 & 0 & 4 & 16 & 13 & 65 & 17 & 81 \\
\hline $\mathbf{3}$ & 0 & 0 & 1 & 2 & 13 & 39 & 3 & 12 & 0 & 0 & 17 & 53 \\
\hline $\mathbf{4}$ & 0 & 0 & 2 & 4 & 6 & 18 & 9 & 36 & 0 & 0 & 17 & 58 \\
\hline $\mathbf{5}$ & 1 & 1 & 0 & 0 & 6 & 18 & 10 & 40 & 0 & 0 & 17 & 59 \\
\hline $\mathbf{6}$ & 0 & 0 & 2 & 4 & 0 & 0 & 6 & 24 & 9 & 45 & 17 & 73 \\
\hline $\mathbf{7}$ & 0 & 0 & 1 & 2 & 0 & 0 & 11 & 44 & 5 & 25 & 17 & 71 \\
\hline $\mathbf{8}$ & 0 & 0 & 1 & 2 & 5 & 15 & 10 & 40 & 1 & 5 & 17 & 62 \\
\hline $\mathbf{9}$ & 0 & 0 & 0 & 0 & 0 & 0 & 2 & 8 & 15 & 75 & 17 & 83 \\
\hline 10 & 1 & 1 & 0 & 0 & 1 & 3 & 2 & 8 & 13 & 65 & 17 & 77 \\
\hline $\mathbf{1 1}$ & 0 & 0 & 0 & 0 & 0 & 0 & 7 & 28 & 10 & 50 & 17 & 78 \\
\hline $\mathbf{1 2}$ & 0 & 0 & 0 & 0 & 0 & 0 & 9 & 36 & 8 & 40 & 17 & 76 \\
\hline $\mathbf{1 3}$ & 0 & 0 & 0 & 0 & 2 & 6 & 13 & 52 & 2 & 10 & 17 & 68 \\
\hline $\mathbf{1 4}$ & 0 & 0 & 0 & 0 & 0 & 0 & 15 & 60 & 2 & 10 & 17 & 70 \\
\hline $\mathbf{1 5}$ & 0 & 0 & 1 & 2 & 2 & 6 & 12 & 48 & 2 & 10 & 17 & 66 \\
\hline $\mathbf{1 6}$ & 0 & 0 & 0 & 0 & 0 & 0 & 3 & 12 & 14 & 70 & 17 & 82 \\
\hline Rata- & 2 & 2 & 8 & 16 & 35 & 105 & 120 & 480 & 107 & 535 & 272 & 113 \\
\hline
\end{tabular}

Tabel 3. Ranting Scala Angket

Skor total hasil angket

Standar skor tertinggi $x 100 \%$

Berdasarkaan data yang diperoleh dari 17 responden dengan jumlah item angket sebanyak 16 maka skor ideal untuk angket tersebut 
adalah 16 item x 17 responden x 5 (skor tertinggi tiap item) $=1360$. Diketahui jumlah skor total sesuai dengan data penyebaran angket adalah sebesar 1138. Presentase angket dapat dihitung dengan rumus sebagai berikut:

Diketahui:

Skor total hasil angket $=1138$

Standar skor tertinggi $=1360$

Jadi, persentase angket:

1138

\section{0}

$$
x 100 \%=83 \%
$$

Skor tersebut tergolong pada kategori kuat yang berada di antara $80 \%-100 \%$.

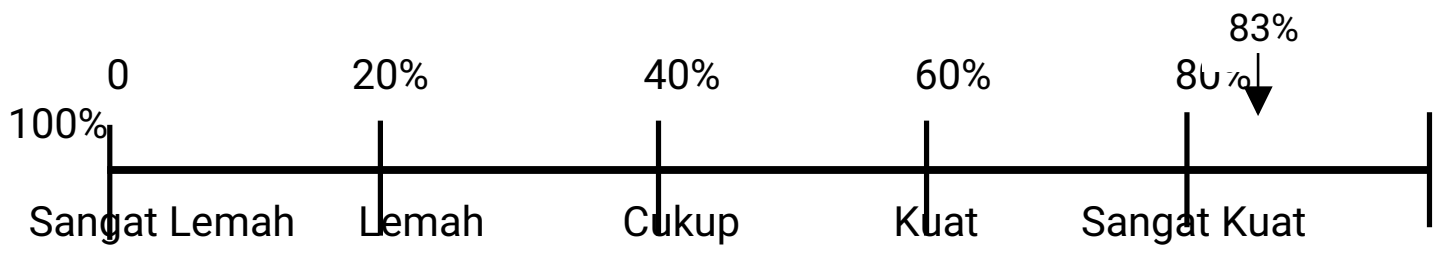

Berdasarkan kategori angket yang tergolong sangat kuat sesuai dengan data di atas, peneliti menyimpulkan bahwa Penerapan media pembelajaran bahasa arab berbasis android dapat menumbuhkan minat, semangat dan keaktifan siswa dalam belajar bahasa arab di kelas sepuluh MA Salaiyah Kota Cirebon.

\section{Kesimpulan}

Media pembelajaran bahasa arab berbasis android ini berjalan baik sesuai dengan fungsinya. Aplikasi media pembelajaran tersebut dapat digunakan pada smartphone berbasis android yang pada dasarnya merupakan aplikasi media pembelajaran yang diharapkan mampu mempermudah guru maupun siswa dalam proses pembelajaran khususnya pada pelajaran bahasa arab. Penerapannya yang sangat sederhana dan mudah sehingga setiap siswa dapat menggunakan media pembelajaran bahasa arab berbasis android kapan saja dan dimana saja.

Sesuai dengan data penyebaran angket kepada seluruh siswa bahwa penerapan media pembelajaran bahasa arab berbasis android di kelas sepuluh MA Salafiyah kota cirebon berada dalam kategori sangat baik dengan nilai pesentase $83 \%$ atau bisa dibilang efektif

\section{Daftar pustaka}

Adam, S., Syastra, \& Taufiq, M. 2015. Pemanfaatan Media Pembelajaran Berbasis Teknologi Informasi bagi Siswa Kelas X SMA Ananda Batam. CBIS Journal, 3(2). 
Arikunto, S. 2013. Prosedur Penelitian : Suatu Pendekatan Praktik. Jakarta: Rineka Cipta.

Arsyad, A. 2013. Media Pembelajaran. Jakarta: Rajawali Press.

Chadeja, N., Salsabila, A. F., \& Azizah, N. N. (2017). Penggunaan Smartphone pada Kontruksi Belajar Siswa MTs Negeri 7 Model Jakarta. Al-Izzah:Jurnal Hasil-Hasil Penelitian, 13(02), 240-254.

Darmawan, D. 2012. Teknologi Pembelajaran. Bandung: PT. Remaja Rosdakarya.

Heriyanto, A. P. 2016. Mobile Phone Forensics: Theory: Mobile Phone Forensics and Security Series. Yogyakarta: C.V Andi Offset.

Ikhsan, Lubis, I. R., Sholihah, M., Sugiyarto, \& Jaslin. 2015. Pengembangan Media Mobile Learning Chemondro Berbasis Android Sebagai Suplemen Belajar Siswa SMA. Seminar Nasional Pendidikan Sains (pp. 468-477). Surakarta: FKIP Universitas Negeri Yogyakarta.

Ismanto, E., Novalia, M., \& Herlandy, P. B. 2017. Pemanfaatan Smartphone Andoi Sebagai Media Pembelajaran Bagi Guru SMA Negeri 2 Kota Pekanbaru. Jurnal Untukmu Negeri, 01(01).

Istiyanto, J. E. 2013. Pemograman Smart Phone Menggunakan SDK Android dan Hacking Android. Yogyakarta: Graha Ilmu.

Kustandi, C., \& Bambang, S. 2011. Media Pembelajaran . Bogor: Ghalia Indonesia.

Kuswanto, J., \& Radiansah, F. 2018. Media Pembelajaran Berbasis Android pada Mata Pelajaran Sistem Oprasi Jaringan. Media Infotama, 14(01).

Lestari, \& Yudhanegara. 2015. Penelitian Pendidikan Matematika. Bandung: PT. Refika Aditama.

Maulana, L. 2017. Pengembangan Media Pembelajaran Berbasis Mobile Learning dengan Platorm Android Materi Keselamatan Kerja dan Lingkungan Hidup (K3LH) pada Program Studi Ketenagalistrikan untuk Siswa Sekolah Menengah Kejuruan. E-Jurnal Universitas Negeri Yogyakarta, 7(2).

Sanjaya, W. 2012. Media Komunikasi Pembelajaran. Jakarta: Kencana Prenada.

Sugiyono. 2014. Metode Penelitian Pendidikan (Pendekatan Kuantitatif, Kualitatif dan $R \& D$ ). Bandung: Alfabeta.

Sugiyono. 2017. Metode Penelitian dan Pengembangan. Bandung: Alfabeta.

Sutopo, A. H. 2012. Teknologi Informasi dan Komunikasi dalam Pendidikan. Yogyakarta: Graha Ilmu.

Umar. 2013. Media pendidikan. Jurnal Tarbawinyah, 10(02). 